\title{
Older patients with chronic myeloid leukemia ( $\geq 65$ years) profit more from higher imatinib doses than younger patients: a subanalysis of the randomized CML-Study IV
}

\author{
Ulrike Proetel • Nadine Pletsch • Michael Lauseker • Martin C. Müller • Benjamin Hanfstein • \\ Stefan W. Krause • Lida Kalmanti • Annette Schreiber • Dominik Heim • Gabriela M. Baerlocher • \\ Wolf-Karsten Hofmann • Elisabeth Lange • Hermann Einsele • Martin Wernli • Stephan Kremers • \\ Rudolf Schlag • Lothar Müller • Mathias Hänel • Hartmut Link • Bernd Hertenstein • Markus Pfirrmann • \\ Andreas Hochhaus • Joerg Hasford • Rüdiger Hehlmann • Susanne Saußele • for the German Chronic \\ Myeloid Leukemia Study Group, and the Schweizerische Arbeitsgemeinschaft für Klinische \\ Krebsforschung (SAKK).
}

Received: 14 February 2014 / Accepted: 17 February 2014 / Published online: 22 March 2014

(C) The Author(s) 2014. This article is published with open access at Springerlink.com

\begin{abstract}
The impact of imatinib dose on response rates and survival in older patients with chronic myeloid leukemia in chronic phase has not been studied well. We analyzed data from the German CML-Study IV, a randomized five-arm
\end{abstract}

Data presented in part at the Congress of the European Hematology Association, Berlin, Germany, June 4-7, 2009; at the Annual Meeting of the American Society of Hematology, Orlando (FL), USA, December 4 7, 2010; at the Annual Meeting of the German, Swiss, and Austrian Societies of Hematology and Oncology Basel, Switzerland, September 30-October 4, 2011; and at the Annual Meeting of the American Society of Hematology, New Orleans (LA), USA, December 7-10, 2013.

Trial registration: ClinicalTrials.gov identifier: NCT00055874

UP and NP contributed equally to this manuscript.

Electronic supplementary material The online version of this article (doi:10.1007/s00277-014-2041-0) contains supplementary material, which is available to authorized users.

U. Proetel • N. Pletsch • M. C. Müller • B. Hanfstein • L. Kalmanti •

A. Schreiber · W.-K. Hofmann • R. Hehlmann · S. Saußele $(\bowtie)$

III. Medizinische Klinik, Universitätsmedizin Mannheim der

Universität Heidelberg, Pettenkoferstrasse 22, 68169 Mannheim,

Germany

e-mail: susanne.saussele@medma.uni-heidelberg.de

M. Lauseker • M. Pfirrmann · J. Hasford

Institut für Medizinische Informationsverarbeitung, Biometrie und Epidemiologie, Ludwig-Maximilians-Universität, München,

Germany

S. W. Krause

Medizinische Klinik 5, Universitätsklinikum, Erlangen, Germany

D. Heim

Klinik für Hämatologie, Universitätsspital, Basel, Switzerland treatment optimization study in newly diagnosed BCRABL-positive chronic myeloid leukemia in chronic phase. Patients randomized to imatinib $400 \mathrm{mg}$ /day (IM400) or imatinib $800 \mathrm{mg} /$ day (IM800) and stratified according to age
G. M. Baerlocher

Universitätsklinik für Hämatologie und hämatologisches

Zentrallabor, Inselspital, Bern, Switzerland

\section{E. Lange}

Klinik für Hämatologie, Onkologie und Palliativmedizin, Evangelisches Krankenhaus, Hamm, Germany

H. Einsele

Medizinische Klinik und Poliklinik II, Universitätsklinikum, Würzburg, Germany

M. Wernli

Onkologie/Hämatologie, Kantonsspital, Aarau, Switzerland

S. Kremers

Onkologisches Zentrum, Lebach, Germany 
( $\geq 65$ years vs. $<65$ years) were compared regarding dose, response, adverse events, rates of progression, and survival. The full $800 \mathrm{mg}$ dose was given after a 6-week run-in period with imatinib $400 \mathrm{mg} /$ day. The dose could then be reduced according to tolerability. A total of 828 patients were randomized to IM400 or IM800. Seven hundred eighty-four patients were evaluable (IM400, 382; IM800, 402). One hundred ten patients $(29 \%)$ on IM400 and $83(21 \%)$ on IM800 were $\geq 65$ years. The median dose per day was lower for patients $\geq 65$ years on IM800, with the highest median dose in the first year $(466 \mathrm{mg}$ /day for patients $\geq 65$ years vs. $630 \mathrm{mg} /$ day for patients $<65$ years). Older patients on IM800 achieved major molecular remission and deep molecular remission as fast as younger patients, in contrast to standard dose imatinib with which older patients achieved remissions much later than younger patients. Grades 3 and 4 adverse events were similar in both age groups. Five-year relative survival for older patients was comparable to that of younger patients. We suggest that the optimal dose for older patients is higher than $400 \mathrm{mg} /$ day. ClinicalTrials.gov identifier: NCT00055874

Keywords Chronic myeloid leukemia · Older patients . Different imatinib dose regimens · Early applied higher imatinib dosages

\section{Introduction}

Older patients with chronic myeloid leukemia (CML) are underrepresented in clinical trials as the median age of patients included in clinical trials is lower compared to the general population (54 years [1] vs. $>60$ years [2-4]). The IRIS trial [5], which led to approval of imatinib for chronic-phase (CP) CML, excluded patients over 70 years of age.

The impact of age on therapy and outcome has already been discussed in the interferon alpha (IFN) era [6]. In the

R. Schlag

Hämatologisch-Onkologische Praxis, Würzburg, Germany

L. Müller

MVM Onkologische Schwerpunktpraxis, Leer, Germany

M. Hänel

Klinik für Innere Medizin III, Klinikum, Chemnitz, Germany

H. Link

Medizinische Klinik I, Westpfalz-Klinikum, Kaiserslautern, Germany

B. Hertenstein

Medizinische Klinik I, Klinikum Mitte, Bremen, Germany

A. Hochhaus

Klinik für Innere Medizin II, Universitätsklinikum, Jena, Germany imatinib era, the outcome of older patients with CML has been studied in several trials [7-13]. Most trials stratified patients by age in a group of older and a group of younger patients. Some trials included patients on different imatinib doses, but did not analyze dose effects on treatment response [8-10]. Rosti et al. reported on 284 patients in late CP CML treated with imatinib $400 \mathrm{mg} /$ day. Complete cytogenetic remission (CCR) rates were lower in older patients ( $\geq 65$ years) than in younger patients ( $<65$ years) with more adverse events (AEs) in older patients, but nevertheless, overall survival (OS) was the same in both age groups [7]. Latagliata et al. analyzed 117 patients in early CP CML under imatinib treatment with 300,400 , or $800 \mathrm{mg}$ /day. No significant difference in the rate of CCR was reported in older ( $\geq 65$ years) compared to younger $(<65$ years) patients. AEs (WHO grades 3-4) were more frequent, and rates of dose reduction to $\leq 300 \mathrm{mg} /$ day and discontinuation of imatinib were higher in older patients [8]. Cortes et al. reported on 187 patients in early CP that were treated with imatinib 400 or 600 $800 \mathrm{mg} /$ day. Twenty-six percent of patients were 60 years or older. With a median follow-up of 16 months, similar rates of CCR were observed in both age groups [9]. More recently, Gugliotta et al. reported similar rates of CCR and major molecular remission (MMR) in 115 patients $\geq 65$ years among 559 patients in early $\mathrm{CP}$ treated with imatinib 400 or $800 \mathrm{mg} /$ day [10]. In a multicenter study of high-dose imatinib in 115 newly diagnosed patients in $\mathrm{CP}$, Cortes et al. reported a similar dose intensity and no difference in AEs at any severity for patients $<65$ and $\geq 65$ years. MMR was achieved by $79 \%$ of patients who received at least $90 \%$ dose intensity (RIGHT study) [11]. Two trials addressing specifically older patients for longterm safety and tolerability of imatinib did not investigate dosage effects of imatinib [12, 13].

In contrast to the aforementioned studies, within the randomized CML-Study IV [14], we analyzed the impact of different imatinib dose regimens on response rates in imatinib-treated older CML patients in comparison to younger patients and suggest that the optimal dose for older patients is higher than $400 \mathrm{mg} /$ day.

\section{Methods}

Study design, patients, and goals The CML-Study IV is a five-arm randomized trial comparing imatinib $400 \mathrm{mg}$ /day (IM400) vs. imatinib $800 \mathrm{mg} /$ day (IM800) vs. imatinib $400 \mathrm{mg} /$ day in combination with IFN vs. imatinib $400 \mathrm{mg} /$ day in combination with low-dose cytarabine vs. imatinib after IFN failure in newly diagnosed BCR-ABL-positive CP CML. During a pilot phase of 3 years, only high-risk patients were assigned to imatinib $800 \mathrm{mg} /$ day. In 2005, imatinib 
$800 \mathrm{mg} /$ day was started as a full study arm $[14,15]$. There was no age limit.

Primary and secondary objectives were as described previously [14, 15]. Published analyses comprised impact of remission rates on survival $[14,15]$, identification of prognostic factors $[16,17]$, and outcome of patients transplanted after imatinib pretreatment [18].

To evaluate the efficacy of imatinib in the elderly, patients randomized to IM400 and IM800 were stratified according to median age at diagnosis in western populations [3] ( $\geq 65 \mathrm{vs}$. $<65$ years). For all four groups, effectively administered imatinib dose, time to cytogenetic and molecular remissions, AEs by World Health Organization (WHO) grading, probabilities of progression to accelerated phase (AP) and blast crisis (BC) and OS, and causes of death were analyzed.
Treatment Treatment and dose adaptation were as described previously (see also legend to Table 2) [14, 15].

Definitions and endpoints Definitions for AP, BC, CCR, MMR, and molecular remission $\leq 0.01 \%$ on the international scale $\left(\mathrm{MR}^{4}\right)$ followed the recommendations of the European LeukemiaNet and the standardized definitions of molecular response $[19,20]$. OS was defined as the time between diagnosis and death of any cause whether on or off tyrosine kinase inhibitor (TKI). All living patients were censored at the time of their last visit. In estimating the cumulative incidences (CI) of molecular or cytogenetic remissions, patients were censored at the time they received a second-generation TKI or were transplanted. Risk assignment was made by EURO [21] and EUTOS scores [22].
Fig. 1 Flow diagram of randomized and evaluable patients. $n$ number of patients, IM400 imatinib $400 \mathrm{mg} /$ day, IM800 imatinib $800 \mathrm{mg} /$ day, $C M L$ chronic myeloid leukemia, $C P$ chronic phase, $I C$ informed consent, $O S$ overall survival, $I M$ imatinib, $y$ years, $C C R$ complete cytogenetic remission, $M M R$ major molecular remission, $M R^{4}$ molecular remission $\leq 0.01 \%$ on the international scale

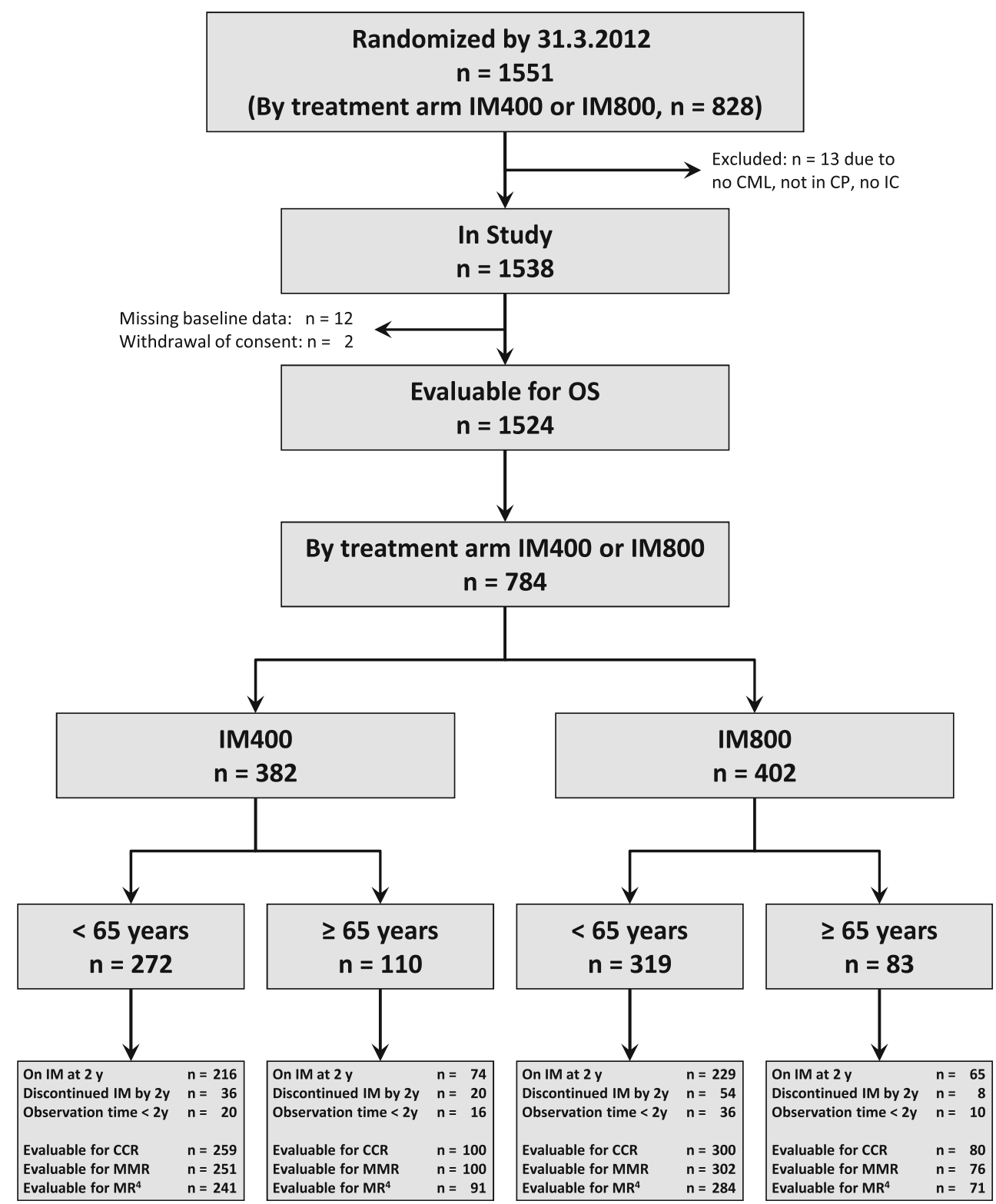


Statistical analysis Baseline characteristics were compared using the Mann-Whitney $U$ test if continuous and the $\mathrm{chi}^{2}$ test if categorical. CI of CCR and MMR were calculated considering competing risks $[23,24]$ defined by AP, BC, and death. CI for AP and BC were calculated with "death without prior progression" as competing event. Comparisons were done by the Gray test [25].

OS curves were calculated by the Kaplan-Meier method and compared by the log-rank test. Relative overall survival was calculated by dividing the observed survival probabilities by the expected survival probability of the general German population matching age and sex. Analyses were according to intention-to-treat; only AEs were analyzed as treated. Level of significance was 0.05 . Since this analysis was not prespecified and $p$ values were not adjusted, the results have to be interpreted as exploratory. Calculations were performed with the SAS software version 9.1.3 and R 2.15.0.

Cytogenetic and molecular analyses Cytogenetic and molecular analyses were performed as described previously $[14,20$, $26,27]$.

Ethics The protocol followed the Declaration of Helsinki and was approved by the ethics committee of the Medizinische Fakultät Mannheim and by local ethics committees of participating centers. Written informed consent was obtained from all patients before they entered the study.

\section{Results}

Patients From July 2002 to March 2012, 1,551 patients were randomized, 828 of these to IM400 or IM800 (Fig. 1). A total of 784 patients were evaluable for follow-up, 382 in the IM400 and 402 in the IM800 arm. One hundred ninety-three patients were $\geq 65$ years, $591<65$ years. Of the older patients, 110 patients were randomized to IM400 and 83 patients to IM800. The median observation time on IM800 was 50.9 months in the elderly and 50.1 months in the younger group, and on IM400, 63.0 months in the elderly and 67.6 months in the younger group. Data entry was closed on May 24, 2012.

The median age of patients was 52 years (IM400, 53 years; IM800, 51 years). Differences between the two age groups were noted in Karnofsky performance index, hemoglobin, spleen size, and white blood cell counts (Table 1).

The median dose per day for the entire observation time was lower for older patients on IM800 $(421 \mathrm{mg} /$ day for patients $\geq 65$ years vs. $556 \mathrm{mg}$ /day for patients $<65$ years) with the highest median dose in the first year $(466 \mathrm{mg} /$ day for patients $\geq 65$ years vs. $630 \mathrm{mg} /$ day for patients $<65$ years), but not different for both age groups on IM400 (400 mg/day each). The dynamics of dose adaptation were analyzed in 3month periods during the first 24 months of treatment for all four patients groups (Table 2). Cutoff values of 390 and $790 \mathrm{mg} /$ day have been chosen to distinguish between the patients that really changed dose and those that only

Table 1 Characteristics of patients at baseline

\begin{tabular}{|c|c|c|c|c|c|c|}
\hline \multirow[b]{2}{*}{ Age (years), $(n)$} & & \multicolumn{2}{|l|}{ IM400 } & \multicolumn{2}{|l|}{ IM800 } & \multirow{2}{*}{$\begin{array}{l}p \text { value, } \\
\text { IM400/IM } 800 \text { combined } \\
<65 \text { vs. } \geq 65\end{array}$} \\
\hline & & $<65(272)$ & $\geq 65(110)$ & $<65(319)$ & $\geq 65(83)$ & \\
\hline \multicolumn{2}{|c|}{ Age (years), median (range) } & $48(16-64)$ & $70(65-88)$ & $46(18-64)$ & $69(65-85)$ & - \\
\hline \multicolumn{2}{|l|}{ Sex female $(\%)$} & 38 & 45 & 41 & 41 & ns \\
\hline \multirow[t]{3}{*}{ Karnofsky index (\%) } & $0-85$ & 11 & 16 & 10 & 18 & 0.03 \\
\hline & $90-95$ & 31 & 38 & 31 & 30 & 0.03 \\
\hline & 100 & 58 & 46 & 59 & 52 & 0.03 \\
\hline \multicolumn{2}{|c|}{ Hemoglobin (g/dl), median (range) } & $12.1(4.9-17.5)$ & $12.8(6.4-16.2)$ & $12.1(4.7-19.1)$ & $12.4(6.5-15.7)$ & $<0.01$ \\
\hline \multicolumn{2}{|c|}{ White blood cell count $\times 10^{9} / 1$, median (range) } & $81.6(5.7-574)$ & $58.0(6.6-582)$ & $93.8(2.6-554)$ & $43.8(5.1-570)$ & $<0.01$ \\
\hline \multicolumn{2}{|c|}{ Platelets $\times 10^{9} / 1$, median (range) } & $373(89-2,419)$ & $390(58-2,337)$ & $388(39-2,582)$ & $400(88-2,716)$ & ns \\
\hline \multicolumn{2}{|c|}{$\begin{array}{l}\text { Spleen size ( } \mathrm{cm} \text { below costal margin), median } \\
\text { (range) }\end{array}$} & $2(0-28)$ & $0(0-16)$ & $2(0-30)$ & $0(0-23)$ & $<0.01$ \\
\hline \multirow[t]{3}{*}{ EURO score $(\%)$} & Low & 45 & 11 & 45 & 12 & $\mathrm{nd}^{\mathrm{a}}$ \\
\hline & Intermediate & 42 & 77 & 42 & 72 & $\mathrm{nd}^{\mathrm{a}}$ \\
\hline & High & 13 & 12 & 13 & 16 & $\mathrm{nd}^{\mathrm{a}}$ \\
\hline \multirow[t]{2}{*}{ EUTOS score $(\%)$} & Low & 87 & 91 & 85 & 86 & ns \\
\hline & High & 13 & 9 & 15 & 14 & ns \\
\hline
\end{tabular}

$n$ number of patients, $I M 400$ imatinib $400 \mathrm{mg} /$ day, IM800 imatinib $800 \mathrm{mg} / \mathrm{day}$, $n s$ not significant, $n d$ not done

${ }^{\text {a }}$ Since the EURO score depends on age by definition, no test was conducted 
Table 2 Dose adaptation of imatinib during the first 24 months

\begin{tabular}{|c|c|c|c|c|}
\hline & & IM40 & & IM800 \\
\hline $\begin{array}{l}\text { Age (years) } \\
\text { Months }\end{array}$ & Doses & $<65$ & $\geq 65$ & $<65$ \\
\hline
\end{tabular}

\begin{tabular}{|c|c|c|c|c|c|}
\hline & Median (mg/day) & & & & \\
\hline $0-3$ & & 400 & 400 & 563 & 472 \\
\hline $3-6$ & & 400 & 400 & 773 & 494 \\
\hline $6-9$ & & 400 & 400 & 629 & 400 \\
\hline $9-12$ & & 400 & 400 & 600 & 400 \\
\hline $12-15$ & & 400 & 400 & 600 & 400 \\
\hline $15-18$ & & 400 & 400 & 600 & 400 \\
\hline $18-21$ & & 400 & 400 & 600 & 400 \\
\hline \multirow[t]{2}{*}{$21-24$} & & 400 & 400 & 600 & 400 \\
\hline & $<390$ mg/day (\%) & & & & \\
\hline $0-3$ & & 3.5 & 4.9 & 1.3 & 0.0 \\
\hline $3-6$ & & 6.4 & 4.0 & 4.3 & 2.6 \\
\hline $6-9$ & & 5.8 & 3.2 & 3.6 & 0.0 \\
\hline $9-12$ & & 4.9 & 3.4 & 2.2 & 0.0 \\
\hline $12-15$ & & 3.4 & 4.7 & 2.0 & 1.5 \\
\hline $15-18$ & & 3.2 & 3.7 & 1.3 & 1.6 \\
\hline $18-21$ & & 2.8 & 3.8 & 2.2 & 0.0 \\
\hline \multirow[t]{2}{*}{$21-24$} & & 2.5 & 4.0 & 2.4 & 0.0 \\
\hline & $390-410$ mg/day (\%) & & & & \\
\hline $0-3$ & & 94.6 & 94.1 & 21.8 & 39.0 \\
\hline $3-6$ & & 91.0 & 95.0 & 20.8 & 36.8 \\
\hline $6-9$ & & 89.2 & 95.7 & 32.2 & 58.0 \\
\hline $9-12$ & & 87.7 & 94.3 & 41.1 & 62.1 \\
\hline $12-15$ & & 89.0 & 92.9 & 41.7 & 69.1 \\
\hline $15-18$ & & 87.8 & 87.7 & 43.0 & 68.9 \\
\hline $18-21$ & & 88.2 & 88.8 & 41.6 & 70.7 \\
\hline \multirow[t]{2}{*}{$21-24$} & & 86.4 & 86.7 & 44.5 & 71.7 \\
\hline & $>410-599$ mg/day (\%) & & & & \\
\hline $0-3$ & & 1.5 & 0.9 & 41.6 & 36.6 \\
\hline $3-6$ & & 1.1 & 0.0 & 11.6 & 23.7 \\
\hline $6-9$ & & 3.1 & 1.1 & 9.2 & 8.7 \\
\hline $9-12$ & & 4.5 & 2.3 & 4.5 & 12.1 \\
\hline $12-15$ & & 3.8 & 0.0 & 4.0 & 3.4 \\
\hline $15-18$ & & 2.7 & 6.2 & 3.4 & 3.3 \\
\hline $18-21$ & & 2.4 & 3.8 & 3.1 & 3.5 \\
\hline \multirow[t]{2}{*}{$21-24$} & & 4.0 & 2.7 & 1.0 & 3.8 \\
\hline & 600-790 mg/day (\%) & & & & \\
\hline $0-3$ & & 0.4 & 0.0 & 14.5 & 8.5 \\
\hline $3-6$ & & 0.8 & 0.0 & 12.9 & 18.4 \\
\hline $6-9$ & & 1.5 & 0.0 & 7.1 & 15.9 \\
\hline $9-12$ & & 2.1 & 0.0 & 3.4 & 10.6 \\
\hline $12-15$ & & 0.0 & 2.4 & 4.4 & 8.8 \\
\hline $15-18$ & & 4.1 & 0.0 & 9.8 & 6.6 \\
\hline $18-21$ & & 4.2 & 0.0 & 9.7 & 8.6 \\
\hline $21-24$ & & 4.0 & 0.0 & 8.1 & 9.4 \\
\hline
\end{tabular}

Table 2 (continued)

\begin{tabular}{|c|c|c|c|c|c|}
\hline \multirow[b]{2}{*}{$\begin{array}{l}\text { Age (years) } \\
\text { Months }\end{array}$} & \multirow[b]{2}{*}{ Doses } & \multicolumn{2}{|c|}{ IM400 } & \multicolumn{2}{|c|}{ IM800 } \\
\hline & & $<65$ & $\geq 65$ & $<65$ & $\geq 65$ \\
\hline & $>790-800 \mathrm{mg} /$ day $(\%)$ & & & & \\
\hline $0-3$ & & 0.0 & 0.0 & 18.8 & 15.9 \\
\hline $3-6$ & & 0.8 & 1.0 & 47.5 & 18.4 \\
\hline $6-9$ & & 0.4 & 0.0 & 44.3 & 17.4 \\
\hline $9-12$ & & 0.8 & 0.0 & 44.8 & 15.2 \\
\hline $12-15$ & & 0.0 & 0.0 & 41.7 & 16.2 \\
\hline $15-18$ & & 2.3 & 1.2 & 42.6 & 19.7 \\
\hline $18-21$ & & 2.4 & 3.8 & 42.9 & 17.2 \\
\hline $21-24$ & & 3.0 & 4.0 & 43.5 & 0.0 \\
\hline
\end{tabular}

Initial treatment for IM400 was imatinib $400 \mathrm{mg}$ /day once daily. In case of suboptimal response, a dose increase to 600 or $800 \mathrm{mg}$ /day was permitted. For IM800, the full $800 \mathrm{mg}$ dose was given after a 6-week run-in period with imatinib $400 \mathrm{mg} /$ day to avoid excessive cytopenias. The dose could then be reduced according to tolerability for maximum patients' adherence and to avoid clinical risks

IM400 imatinib $400 \mathrm{mg} /$ day, IM800 imatinib $800 \mathrm{mg} /$ day, \% percent of patients who were still on imatinib at the respective time points and received these doses

discontinued imatinib for one or two days, e.g., due to AEs. The $47.5 \%$ of younger patients and $18.4 \%$ of older patients on IM800 received an imatinib dosage between 790 and $800 \mathrm{mg} / \mathrm{day}$ in the second 3-month period with the highest dose in older patients at $494 \mathrm{mg} /$ day in the second 3-month period. Thereafter, the dose decreased to $400 \mathrm{mg}$ /day by months 6-9. In younger patients, the highest median dosage on IM800 was $773 \mathrm{mg} /$ day in the second 3-month period, which decreased to $600 \mathrm{mg}$ /day by months $9-12$.

Comparison of responses If treated with IM800, older patients achieved MMR and $\mathrm{MR}^{4}$ as fast as younger patients (Fig. 2a, b). Median times to MMR were 11.9 vs. 10.5 months, respectively. Median times to $\mathrm{MR}^{4}$ were 24.2 vs. 26.1 months, respectively. In contrast, if treated with IM400, older patients achieved MMR and $\mathrm{MR}^{4}$ significantly later than younger patients (MMR $p=0.013$; Fig. 2a; $\mathrm{MR}^{4} p=0.012$; Fig. 2b). Median times to MMR were 18.1 vs. 15.9 months, and to $\mathrm{MR}^{4} 54.4$ vs. 33.3 months, respectively. Regarding CCR, median times to CCR on IM800 were 9.0 vs. 9.7 months, and on IM400 14.8 vs. 12.0 months, respectively. The difference between age groups on IM400 did not reach significance (Fig. 2c).

AEs One hundred sixty-nine patients $\geq 65$ years and 542 patients $<65$ years were evaluated for AEs during the initial 24 months. There was no significant difference between age groups for higher-grade (WHO grades 3 and 4) hematologic 

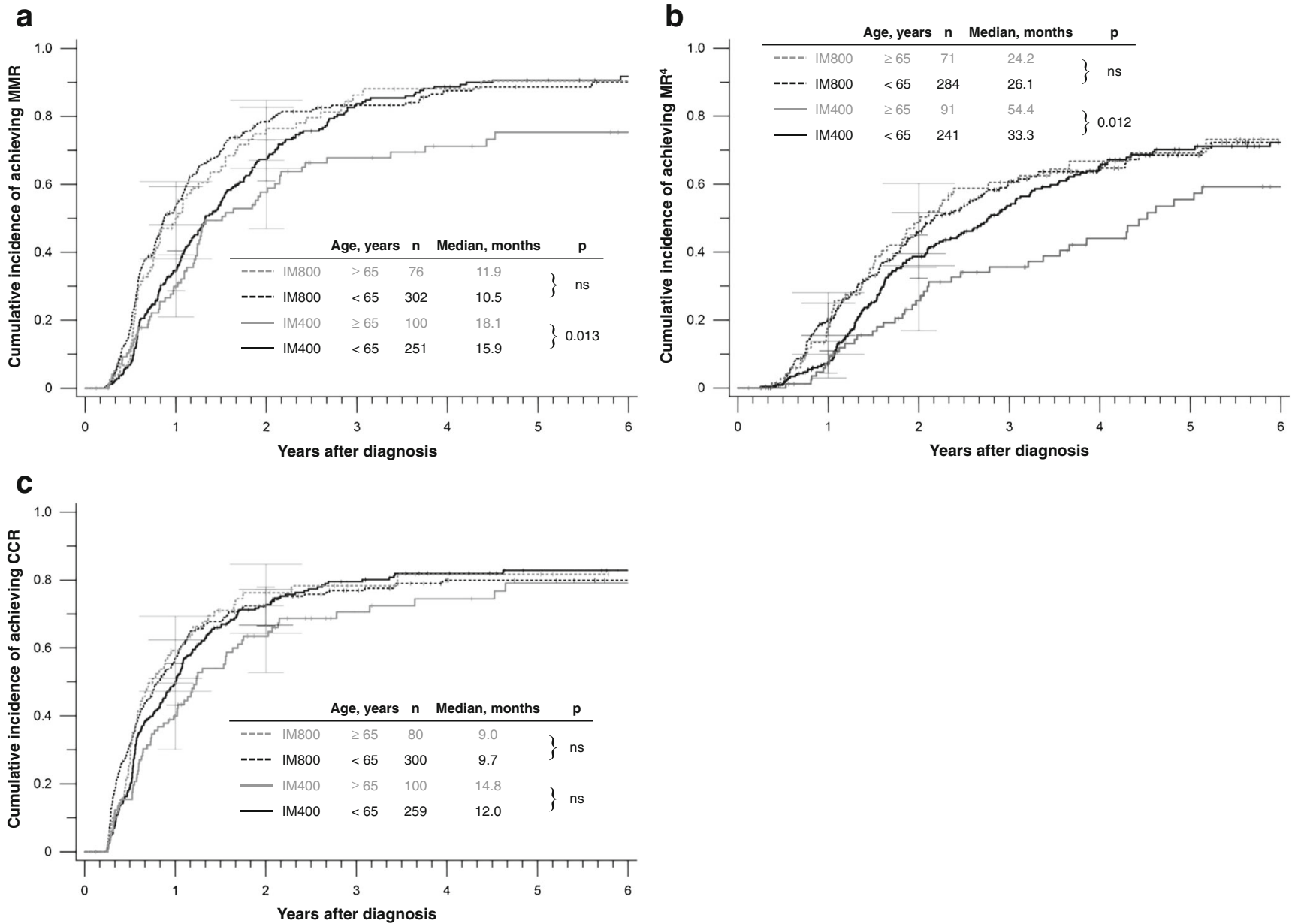

Fig. 2 Molecular and cytogenetic remissions according to treatment groups. a Cumulative incidences of MMR, b cumulative incidences of MR ${ }^{4}$, and $\mathbf{c}$ cumulative incidences of CCR. $M M R$ major molecular remission, $M R^{4}$ molecular remission $\leq 0.01 \%$ on the international scale, $C C R$ complete cytogenetic remission, $n$ number of patients, IM400 imatinib $400 \mathrm{mg} /$ day, IM800 imatinib $800 \mathrm{mg} / \mathrm{day}$, $n s$ not significant

AEs. Leukocytopenia (all grades) in patients treated on IM800 and neurological AEs (all grades) in patients treated on IM400 were significantly less frequent in older patients $(p=0.009$ and $p=0.03$, respectively). Some higher-grade non-hematologic AEs were significantly more frequent in older than in younger patients (IM400: dermatologic AEs, $p=0.01$; IM800: infections, $p=0.03$ ) (Table 3).

Progression and survival There was no difference between age groups in probabilities of progression to $\mathrm{AP}$ or $\mathrm{BC}$ in an analysis according to treatment groups (Fig. 3). Five-year OS for patients $\geq 65$ years was $78.2 \%$ (IM400) and $87.5 \%$ (IM800), and for patients $<65$ years $92.8 \%$ (IM400) and $92.5 \%$ (IM800). Taking into account the German population adjusted for age and sex [28], 5-year relative survival was $90.7 \%$ for IM400 and $100.8 \%$ for IM800, respectively, for the older patients and $94.9 \%$ and $94.4 \%$, respectively, for the younger patients. In the elderly, death due to second malignancies was more frequent than death due to progression (Table 4).

\section{Discussion}

This is the first report that analyzes the effect of different imatinib dose regimens in older vs. younger patients with CML. The most important finding of our analysis is that older patients on IM800 had no delay in reaching MMR and MR ${ }^{4}$, as this was the fact with standard-dose imatinib where MMR and $\mathrm{MR}^{4}$ were achieved significantly later than in younger patients. We conclude that the superiority of the response rates to IM800 was more pronounced in the older than in the younger group. This effect is remarkable as the median dose for older patients on IM800 was lower than that of younger patients and only moderately higher than in older patients on IM400. The result is in line with previous reports of this study that superior cytogenetic and molecular remission rates were reached in patients with IM800 [14]. We think that this finding is important, since superior molecular remission rates have been shown to correlate with better survival $[14,15]$.

To avoid higher-grade AEs on IM800, imatinib was adapted to tolerability in both age groups. Dose reductions 
Table 3 Adverse events during the initial 24 months $n$ number of patients, $I M 400$

imatinib $400 \mathrm{mg} /$ day, IM800

imatinib $800 \mathrm{mg} /$ day, $W H O$

World Health Organization, \% percent of patients who had the described adverse events, $A E s$ adverse events

${ }^{a}$ Number of patients for whom an analysis was available. A total of 73 out of 784 patients were not evaluable due to short observation time $(<24$ months $)$ and being alive

${ }^{\mathrm{b}}$ In addition, 276 patients were not evaluable due to anemia grades 1-4 at baseline

${ }^{\mathrm{c}}$ In addition, 5 patients were not evaluable due to leukocytopenia grades $1-4$ at baseline

${ }^{\mathrm{d}}$ In addition, 35 patients were not evaluable due to thrombocytopenia grades $1-4$ at baseline

${ }^{\mathrm{e}}$ In addition, 8 patients were not evaluable due to missing information about non-hematologic adverse events

${ }^{\mathrm{f}}$ In addition, 32 patients were not evaluable due to anemia grades 3-4 at baseline

\begin{tabular}{|c|c|c|c|c|}
\hline \multirow[b]{2}{*}{ Age (years), $(n)$} & \multicolumn{2}{|l|}{ IM400 } & \multicolumn{2}{|l|}{ IM800 } \\
\hline & $<65\left(254^{\mathrm{a}}\right)$ & $\geq 65\left(96^{\mathrm{a}}\right)$ & $<65\left(288^{\mathrm{a}}\right)$ & $\geq 65\left(73^{\mathrm{a}}\right)$ \\
\hline \multicolumn{5}{|l|}{ Adverse events } \\
\hline \multicolumn{5}{|l|}{ WHO grades $1-4(\%)$} \\
\hline Anemia $^{\mathrm{b}}$ & 51.4 & 61.4 & 53.1 & 54.9 \\
\hline Leukocytopenia $^{\mathrm{c}}$ & 56.7 & 58.3 & 64.7 & 48.0 \\
\hline Thrombocytopenia $^{\mathrm{d}}$ & 36.9 & 34.5 & 35.6 & 32.9 \\
\hline Myalgia/arthralgia ${ }^{\mathrm{e}}$ & 19.0 & 11.7 & 28.9 & 20.8 \\
\hline Dermatologic $\mathrm{AEs}^{\mathrm{e}}$ & 12.6 & 14.9 & 27.5 & 33.3 \\
\hline Edema $^{\mathrm{e}}$ & 24.9 & 24.5 & 40.1 & 45.8 \\
\hline Gastrointestinal $\mathrm{AEs}^{\mathrm{e}}$ & 26.1 & 23.4 & 48.2 & 47.2 \\
\hline Neurological AEs ${ }^{\mathrm{e}}$ & 15.4 & 6.4 & 16.9 & 20.8 \\
\hline Infection $^{\mathrm{e}}$ & 6.3 & 4.3 & 12.0 & 15.3 \\
\hline Fatigue $^{\mathrm{e}}$ & 14.2 & 8.5 & 19.7 & 15.3 \\
\hline Allergy/immunology ${ }^{\mathrm{e}}$ & 1.2 & 4.3 & 2.5 & 0 \\
\hline Constitutional symptoms $^{\mathrm{e}}$ & 5.9 & 3.2 & 14.8 & 12.5 \\
\hline Other ${ }^{\mathrm{e}}$ & 31.2 & 30.9 & 42.7 & 45.2 \\
\hline \multicolumn{5}{|l|}{ WHO grades 3 and $4(\%)$} \\
\hline Anemia $^{\mathrm{f}}$ & 3.8 & 6.4 & 5.1 & 7.0 \\
\hline Leukocytopenia & 1.6 & 3.1 & 5.2 & 5.5 \\
\hline Thrombocytopenia & 3.9 & 4.2 & 7.7 & 8.2 \\
\hline Myalgia/arthralgia $^{\mathrm{e}}$ & 2.8 & 1.1 & 2.5 & 1.4 \\
\hline Dermatologic $\mathrm{AEs}^{\mathrm{e}}$ & 0.4 & 5.4 & 2.8 & 2.8 \\
\hline Edema $^{\mathrm{e}}$ & 1.2 & 0 & 1.4 & 5.6 \\
\hline Gastrointestinal AEs ${ }^{\mathrm{e}}$ & 2.0 & 1.1 & 3.2 & 4.8 \\
\hline Neurological AEs ${ }^{\mathrm{e}}$ & 2.0 & 0 & 2.5 & 4.2 \\
\hline Infection $^{\mathrm{e}}$ & 0.8 & 0 & 2.5 & 8.3 \\
\hline Fatigue $^{\mathrm{e}}$ & 0.4 & 0 & 2.5 & 1.4 \\
\hline Allergy/immunology ${ }^{\mathrm{e}}$ & 0 & 1.1 & 0.4 & 0 \\
\hline Constitutional symptoms ${ }^{\mathrm{e}}$ & 0.4 & 0 & 0.7 & 0 \\
\hline Other ${ }^{\mathrm{e}}$ & 6.3 & 9.6 & 11.6 & 12.5 \\
\hline
\end{tabular}

Given the observation that the effect of higher imatinib dosages applied early in the course of treatment is more pronounced in older than in younger patients, this could explain the difference between results of this study and another randomized trial of imatinib $400 \mathrm{vs.} 800 \mathrm{mg} /$ day [29], since in the other study, the median age of the study population was lower (47 vs. 52 years in our study) and patients older than 75 years were excluded, resulting in a lower number of patients $\geq 65$ years $(15.5 \%$ (personal written communication, C. Piccolo, Novartis, November 18,2013 ) vs. $24.6 \%$ in our study).

Since the median dosage for patients on the IM400 arm was $400 \mathrm{mg} /$ day for both age groups and the proportion of patients who received doses $<390 \mathrm{mg} /$ day was similar, the significantly later achievement of MMR and $\mathrm{MR}^{4}$ in older patients on IM400 cannot be explained by non-adherence to the prescribed medication and a lower than $400 \mathrm{mg}$ dosage. 
Fig. 3 Progression to $\mathrm{AP}$ and $\mathrm{BC}$ according to treatment groups. $A P$ accelerated phase, $B C$ blast crisis, $n$ number of patients, $C I$ imatinib $400 \mathrm{mg} /$ day, IM800 imatinib $800 \mathrm{mg} /$ day, $n s$ not significant cumulative incidence, $I M 400$

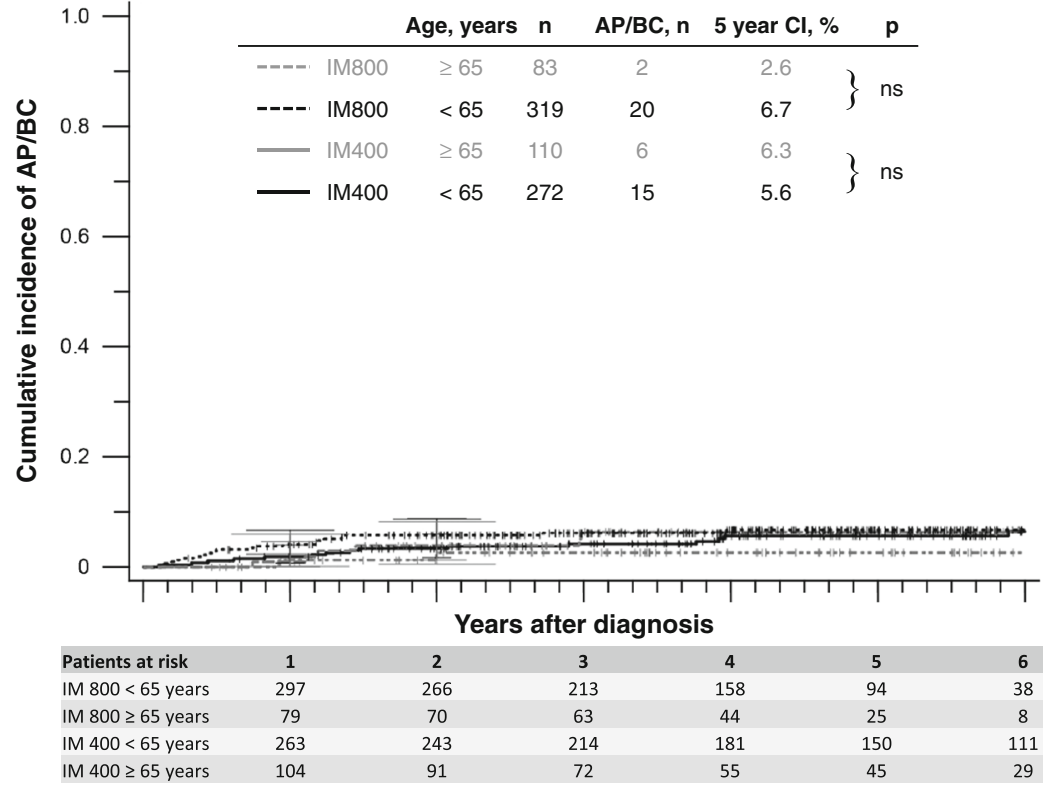

The baseline characteristics beyond age seem to have no influence, but the proportion of patients with lower Karnofsky index was significantly higher in older patients.

To compare survival between age groups, the German population adjusted for age and sex [28] was taken into account. OS was reduced in older compared to younger patients due to a generally reduced life expectancy of older people, whereas the 5-year relative survival of older patients was comparable with that of younger patients. Nevertheless, it is important to note that a bias in favor of the study patients is likely. The relative survival estimates may be too optimistic, since the exclusion criteria of CML-Study IV prevented the participation of some of the frailest patients, e.g., those with other neoplasias in need of treatment or with conditions preventing study compliance and thus with a supposedly reduced life expectancy. This would explain the better survival in older patients on IM800 (100.8 \% at 5 years) than in the general population.

In the pre-imatinib era, older age has been a poor prognostic factor in CML [21, 30]. In the EUTOS score, which was based on patients treated with imatinib, age is not included any more. Since the EUTOS score refers to the endpoint CCR at 18 months [22], it has to be seen in the future whether age is still an important risk factor for survival in patients with CML under imatinib.

In conclusion, in older patients, higher molecular response rates similar to younger patients are achievable with higher imatinib doses applied early in the course of treatment, in

Table 4 Causes of death

$n$ number of patients, $I M 400$ imatinib $400 \mathrm{mg} /$ day, IM800 imatinib $800 \mathrm{mg}$ /day, $A P$ accelerated phase, $B C$ blast crisis, $C P$ chronic phase

\begin{tabular}{|c|c|c|c|c|}
\hline \multirow[b]{2}{*}{ Age (years), $(n)$} & \multicolumn{2}{|l|}{ IM400 } & \multicolumn{2}{|l|}{ IM800 } \\
\hline & $<65(272)$ & $\geq 65(110)$ & $<65$ (319) & $\geq 65(83)$ \\
\hline Total deaths $(n)$ & 23 & 21 & 19 & 6 \\
\hline \multicolumn{5}{|l|}{ Causes $(n)$} \\
\hline Progression to $\mathrm{AP} / \mathrm{BC}$ & 8 & 4 & 9 & 1 \\
\hline Transplantation related & 3 & 0 & 4 & 0 \\
\hline Infection in $\mathrm{CP}$ & 2 & 0 & 2 & 1 \\
\hline Secondary malignancy & 1 & 8 & 1 & 2 \\
\hline Bleeding & 1 & 0 & 1 & 0 \\
\hline Cardiopulmonary & 2 & 2 & 1 & 1 \\
\hline Renal insufficiency & 0 & 2 & 0 & 1 \\
\hline Thromboembolic/ischemic (not cardiac) & 0 & 1 & 1 & 0 \\
\hline Suicide & 0 & 1 & 0 & 0 \\
\hline Others & 3 & 0 & 0 & 0 \\
\hline Unknown & 3 & 3 & 0 & 0 \\
\hline
\end{tabular}


contrast to standard-dose imatinib. It seems that the optimal daily dose for patients with CP CML is higher than $400 \mathrm{mg}$, irrespective of age.

Acknowledgments The authors would like to thank Gabriele Bartsch, Uwe Böhm, Elke Matzat, Sabine Dean, Ute Kossak-Roth, Barbara Müller, Regina Pleil-Lösch, Nicole Schomber, Inge Stalljann, Andrea Poetsch, the Steering Group (Rüdiger Hehlmann, Gerhard Ehninger, Joerg Hasford, Andreas Hochhaus, Dieter Hossfeld, Hans-Jochem Kolb, Stefan W. Krause, Christoph Nerl, Andreas Neubauer, Dominik Heim, Gabriela M. Baerlocher, Hermann Heimpel), and all CML trial participants. The CML-Study IV is supported by the Deutsche Krebshilfe (Nr. 106642 and 109588), Novartis, (Nürnberg, Germany), Kompetenznetz für Akute and Chronische Leukämien (BMBF 01GI0270), José-Carreras Leukämiestiftung (DJCLS H09/01f, H06/04v, H03/01, R05/23), the European LeukemiaNet (LSHC-CT-2004-503216), Roche, and Essex Pharma.

Conflict of interest MCM was supported by Novartis (consultation or other fees, research funding, other relationships), Bristol-Myers Squibb (consultation or other fees, research funding, other relationships), and ARIAD (consultation or other fees, research funding, other relationships). MP was also supported by Novartis (consultation or other fees) and Bristol-Myers Squibb (lecture fees). AH received financial support from Novartis (consultation or other fees, lecture fees, research funding), Bristol-Myers Squibb (consultation or other fees, lecture fees), ARIAD (consultation or other fees, lecture fees), and Pfizer (consultation or other fees, lecture fees). RH was supported by Bristol-Myers Squibb (consultation or other fees, research funding) and Novartis (research funding). SS received sponsorship from Novartis (consultation or other fees, research funding, other relationships), Bristol-Myers Squibb (consultation or other fees, research funding), and Pfizer (consultation or other fees).

Open Access This article is distributed under the terms of the Creative Commons Attribution License which permits any use, distribution, and reproduction in any medium, provided the original author(s) and the source are credited.

\section{References}

1. Rohrbacher M, Berger U, Hochhaus A, Metzgeroth G, Adam K, Lahaye T, Saussele S, Müller MC, Hasford J, Heimpel H, Hehlmann $\mathrm{R}$ (2009) Clinical trials underestimate the age of chronic myeloid leukemia (CML) patients. Incidence and median age of $\mathrm{Ph} / \mathrm{BCR}$ ABL-positive CML and other chronic myeloproliferative disorders in a representative area in Germany. Leukemia 23(3):602-604. doi:10. 1038/leu.2008.245

2. Björkholm M, Ohm L, Eloranta S, Derolf A, Hultcrantz M, Sjöberg J, Andersson T, Höglund M, Richter J, Landgren O, Kristinsson SY, Dickman PW (2011) Success story of targeted therapy in chronic myeloid leukemia: a population-based study of patients diagnosed in Sweden from 1973 to 2008. J Clin Oncol 29(18):2514-2520. doi:10. 1200/jco.2011.34.7146

3. Altekruse SF, Kosary CL, Krapcho M, Neyman N, Aminou R, Waldron W, Ruhl J, Howlader N, Tatalovich Z, Cho H, Mariotto A, Eisner MP, Lewis DR, Cronin K, Chen HS, Feuer EJ, Stinchcomb DG, Edwards BK (eds) (based on November 9 SEER data submission, posted to the SEER web site, 2010 ) SEER cancer statistics review, 1975-2007: median age of cancer patients at diagnosis,
2003-2007 by primary cancer site, race and sex. http://seer.cancer. gov/csr/1975 2007/results_single/sect_01 table.11_2pgs.pdf, National Cancer Institute, Bethesda, MD

4. Rohrbacher M, Hasford J (2009) Epidemiology of chronic myeloid leukaemia (CML). Best Pract Res Clin Haematol 22(3):295-302. doi:10.1016/j.beha.2009.07.007

5. Druker BJ, Guilhot F, O'Brien SG, Gathmann I, Kantarjian H, Gattermann N, Deininger MW, Silver RT, Goldman JM, Stone RM, Cervantes F, Hochhaus A, Powell BL, Gabrilove JL, Rousselot P, Reiffers J, Cornelissen JJ, Hughes T, Agis H, Fischer T, Verhoef G, Shepherd J, Saglio G, Gratwohl A, Nielsen JL, Radich JP, Simonsson B, Taylor K, Baccarani M, So C, Letvak L, Larson RA, or the IRIS Investigators (2006) Five-year follow-up of patients receiving imatinib for chronic myeloid leukemia. N Engl J Med 355(23):24082417. doi:10.1056/NEJMoa062867

6. Berger U, Engelich G, Maywald O, Pfirrmann M, Hochhaus A, Reiter A, Metzgeroth G, Gnad U, Hasford J, Heinze B, Heimpel H, Hossfeld DK, Kolb HJ, Loffler H, Pralle H, Queisser W, Hehlmann R, and the German CML-Study Group (2003) Chronic myeloid leukemia in the elderly: long-term results from randomized trials with interferon alpha. Leukemia 17(9):1820-1826. doi:10.1038/sj.leu. 2403042

7. Rosti G, Iacobucci I, Bassi S, Castagnetti F, Amabile M, Cilloni D, Poerio A, Soverini S, Palandri F, Rege Cambrin G, Iuliano F, Alimena G, Latagliata R, Testoni N, Pane F, Saglio G, Baccarani M, Martinelli G (2007) Impact of age on the outcome of patients with chronic myeloid leukemia in late chronic phase: results of a phase II study of the GIMEMA CML Working Party. Haematologica 92(1): 101-105. doi:10.3324/haematol.10239

8. Latagliata R, Breccia M, Carmosino I, Cannella L, De Cuia R, Diverio D, Frustaci A, Loglisci G, Mancini M, Santopietro M, Stefanizzi C, Volpicelli P, Vozella F, Alimena G (2010) "Real- life" results of front-line treatment with Imatinib in older patients $(\geq 65$ years) with newly diagnosed chronic myelogenous leukemia. Leuk Res 34(11):1472-1475. doi:10.1016/j.leukres.2010.07.001

9. Cortes J, Talpaz M, O'Brien S, Giles F, Beth Rios M, Shan J, Faderl S, Garcia-Manero G, Ferrajoli A, Wierda W, Kantarjian H (2003) Effects of age on prognosis with imatinib mesylate therapy for patients with Philadelphia chromosome-positive chronic myelogenous leukemia. Cancer 98(6):1105-1113. doi:10.1002/cncr.11629

10. Gugliotta G, Castagnetti F, Palandri F, Breccia M, Intermesoli T, Capucci A, Martino B, Pregno P, Rupoli S, Ferrero D, Gherlinzoni F, Montefusco E, Bocchia M, Tiribelli M, Pierri I, Grifoni F, Marzocchi G, Amabile M, Testoni N, Martinelli G, Alimena G, Pane F, Saglio G, Baccarani M, Rosti G, and on behalf of the Gruppo Italiano Malattie Ematologiche dell'Adulto CML Working Party (2011) Frontline imatinib treatment of chronic myeloid leukemia: no impact of age on outcome, a survey by the GIMEMA CML Working Party. Blood 117(21):5591-5599. doi:10.1182/blood-2010-12-324228

11. Cortes JE, Kantarjian HM, Goldberg SL, Powell BL, Giles FJ, Wetzler M, Akard L, Burke JM, Kerr R, Saleh M, Salvado A, McDougall K, Albitar M, Radich J, on behalf of the Rationale and Insight for Gleevec High-Dose Therapy (RIGHT) Trial Study Group (2009) High-dose imatinib in newly diagnosed chronic-phase chronic myeloid leukemia: high rates of rapid cytogenetic and molecular responses. J Clin Oncol 27(28):4754-4759. doi:10.1200/jco.2008. 20.3869

12. Rousselot P, Cony-Makhoul P, Nicolini F, Mahon FX, Berthou C, Réa D, Reiffers J, Bornand A, Saint-Jean O, Guilhot J, Guilhot F, on behalf of the French Intergroup For Chronic Myelogenous Leukemia (Fi-LMC) (2013) Long-term safety and efficacy of imatinib mesylate $\left(\right.$ Gleevec ${ }^{\mathbb{R}}$ ) in elderly patients with chronic phase chronic myelogenous leukemia: Results of the AFR04 study. Am J Hematol 88(1):14. doi:10.1002/ajh.23330

13. Sánchez-Guijo FM, Durán S, Galende J, Boqué C, Nieto JB, Balanzat J, Gracia A, García I, Avellaneda-Molina C, Moreno M-V, 
Luño-Fernandez E, Hermosilla M, Sanchez-Varela JM, Dios A, Lopez-Garrido P, Giraldo P, Bargay J, Domingo JM, Soler A, Salinas R, del Cañizo MC (2011) Evaluation of tolerability and efficacy of imatinib mesylate in elderly patients with chronic phase CML: ELDERGLI study. Leuk Res 35(9):1184-1187. doi:10.1016/j. leukres.2011.01.017

14. Hehlmann R, Lauseker M, Jung-Munkwitz S, Leitner A, Mueller MC, Pletsch N, Proetel U, Haferlach C, Schlegelberger B, Balleisen L, Hänel M, Pfirrmann M, Krause SW, Nerl C, Pralle H, Gratwohl A, Hossfeld DK, Hasford J, Hochhaus A, Saussele S, (2011) Tolerability-adapted imatinib $800 \mathrm{mg} / \mathrm{d}$ versus $400 \mathrm{mg} / \mathrm{d}$ versus 400 $\mathrm{mg} / \mathrm{d}$ plus interferon-alpha in newly diagnosed chronic myeloid leukemia. J Clin Oncol 29(12):1634-1642. doi:10.1200/jco.2010. 32.0598

15. Hehlmann R, Müller MC, Lauseker M, Hanfstein B, Fabarius A, Schreiber A, Proetel U, Pletsch N, Pfirrmann M, Haferlach C, Schnittger S, Einsele H, Dengler J, Falge C, Kanz L, Neubauer A, Kneba M, Stegelmann F, Pfreundschuh M, Waller CF, Spiekermann K, Baerlocher GM, Ehninger G, Heim D, Heimpel H, Nerl C, Krause SW, Hossfeld DK, Kolb HJ, Hasford J, Saußele S, Hochhaus A (2014) Deep molecular response (MR4.5) is reached by the majority of imatinib-treated patients, predicts survival, and is achieved faster by optimized high-dose imatinib - results from the randomized CML-Study IV. J Clin Oncol 32(5):415-423. doi:10.1200/JCO. 2013.49.9020

16. Fabarius A, Leitner A, Hochhaus A, Müller MC, Hanfstein B, Haferlach C, Göhring G, Schlegelberger B, Jotterand M, Reiter A, Jung-Munkwitz S, Proetel U, Schwaab J, Hofmann WK, Schubert J, Einsele H, Ho AD, Falge C, Kanz L, Neubauer A, Kneba M, Stegelmann F, Pfreundschuh M, Waller CF, Spiekermann K, Baerlocher GM, Lauseker M, Pfirrmann M, Hasford J, Saussele S, Hehlmann R, and for the Schweizerische Arbeitsgemeinschaft für Klinische Krebsforschung (SAKK) and the German CML Study Group (2011) Impact of additional cytogenetic aberrations at diagnosis on prognosis of CML: long-term observation of 1151 patients from the randomized CML Study IV. Blood 118(26):6760-6768 doi: 10.1182/blood-2011-08-373902

17. Hanfstein B, Müller MC, Hehlmann R, Erben P, Lauseker M, Fabarius A, Schnittger S, Haferlach C, Göhring G, Proetel U, Kolb HJ, Krause SW, Hofmann WK, Schubert J, Einsele H, Dengler J, Hänel M, Falge C, Kanz L, Neubauer A, Kneba M, Stegelmann F, Pfreundschuh M, Waller CF, Branford S, Hughes TP, Spiekermann K, Baerlocher GM, Pfirrmann M, Hasford J, Saußele S, Hochhaus A, for the SAKK and the German CML Study Group (2012) Early molecular and cytogenetic response is predictive for long-term progression-free and overall survival in chronic myeloid leukemia (CML). Leukemia 26(9):2096-2102. doi:10.1038/leu.2012.85

18. Saussele S, Lauseker M, Gratwohl A, Beelen DW, Bunjes D, Schwerdtfeger R, Kolb HJ, Ho AD, Falge C, Holler E, Schlimok G, Zander AR, Arnold R, Kanz L, Dengler R, Haferlach C, Schlegelberger B, Pfirrmann M, Müller MC, Schnittger S, Leitner A, Pletsch N, Hochhaus A, Hasford J, Hehlmann R, and for the German CML-Study Group (2010) Allogeneic hematopoietic stem cell transplantation (allo SCT) for chronic myeloid leukemia in the imatinib era: evaluation of its impact within a subgroup of the randomized German CML Study IV. Blood 115(10):1880-1885. doi:10.1182/blood-2009-08-237115

19. Baccarani M, Deininger MW, Rosti G, Hochhaus A, Soverini S, Apperley JF, Cervantes F, Clark RE, Cortes JE, Guilhot F, HjorthHansen H, Hughes TP, Kantarjian HM, Kim DW, Larson RA, Lipton
JH, Mahon F-X, Martinelli G, Mayer J, Müller MC, Niederwieser D, Pane F, Radich JP, Rousselot P, Saglio G, Saußele S, Schiffer C, Silver R, Simonsson B, Steegmann JL, Goldman JM, Hehlmann R (2013) European LeukemiaNet recommendations for the management of chronic myeloid leukemia: 2013. Blood 122(6):872-884. doi:10.1182/blood-2013-05-501569

20. Cross NCP, White HE, Müller MC, Saglio G, Hochhaus A (2012) Standardized definitions of molecular response in chronic myeloid leukemia. Leukemia 26(10):2172-2175. doi:10.1038/leu.2012.104

21. Hasford J, Pfirrmann M, Hehlmann R, Allan NC, Baccarani M, Kluin-Nelemans JC, Alimena G, Steegmann JL, Ansari H (1998) A new prognostic score for survival of patients with chronic myeloid leukemia treated with interferon alfa. Writing Committee for the Collaborative CML Prognostic Factors Project Group. J Natl Cancer Inst 90(11):850-858. doi:10.1093/jnci/90.11.850

22. Hasford J, Baccarani M, Hoffmann V, Guilhot J, Saussele S, Rosti G, Guilhot F, Porkka K, Ossenkoppele G, Lindoerfer D, Simonsson B, Pfirrmann M, Hehlmann R (2011) Predicting complete cytogenetic response and subsequent progression-free survival in 2060 patients with CML on imatinib treatment: the EUTOS score. Blood 118(3): 686-692. doi:10.1182/blood-2010-12-319038

23. Gooley TA, Leisenring W, Crowley J, Storer BE (1999) Estimation of failure probabilities in the presence of competing risks: new representations of old estimators. Stat Med 18(6):695-706

24. Pfirrmann M, Hochhaus A, Lauseker M, Saußele S, Hehlmann R, Hasford J (2011) Recommendations to meet statistical challenges arising from endpoints beyond overall survival in clinical trials on chronic myeloid leukemia. Leukemia 25(9):1433-1438. doi:10. 1038/leu.2011.116

25. Gray RJ (1988) A class of k-sample tests for comparing the cumulative incidence of a competing risk. Ann Stat 16(3):1141-1154. doi: 10.1214/aos/1176350951

26. Hughes T, Deininger M, Hochhaus A, Branford S, Radich J, Kaeda J, Baccarani M, Cortes J, Cross NC, Druker BJ, Gabert J, Grimwade D, Hehlmann R, Kamel-Reid S, Lipton JH, Longtine J, Martinelli G, Saglio G, Soverini S, Stock W, Goldman JM (2006) Monitoring CML patients responding to treatment with tyrosine kinase inhibitors: review and recommendations for harmonizing current methodology for detecting BCR-ABL transcripts and kinase domain mutations and for expressing results. Blood 108(1):28-37 doi:10.1182/blood-200601-0092

27. Müller MC, Cross NC, Erben P, Schenk T, Hanfstein B, Ernst T, Hehlmann R, Branford S, Saglio G, Hochhaus A (2009) Harmonization of molecular monitoring of CML therapy in Europe. Leukemia 23(11):1957-1963. doi:10.1038/leu.2009.168

28. Statistical Yearbook for the Federal Republic of Germany including "International tables" (2011) Federal Statistical Office, Wiesbaden

29. Cortes JE, Baccarani M, Guilhot F, Druker BJ, Branford S, Kim DW, Pane F, Pasquini R, Goldberg SL, Kalaycio M, Moiraghi B, Rowe JM, Tothova E, De Souza C, Rudoltz M, Yu R, Krahnke T, Kantarjian HM, Radich JP, Hughes TP (2010) Phase III, randomized, open-label study of daily imatinib mesylate $400 \mathrm{mg}$ versus $800 \mathrm{mg}$ in patients with newly diagnosed, previously untreated chronic myeloid leukemia in chronic phase using molecular end points: tyrosine kinase inhibitor optimization and selectivity study. J Clin Oncol 28(3):424 430. doi:10.1200/JCO.2009.25.3724

30. Kantarjian HM, Keating MJ, McCredie KB, Walters R, Talpaz M, Smith TL, Freireich EJ (1987) Old age: a sign of poor prognosis in patients with chronic myelogenous leukemia. South Med J 80(10): $1228-1232$ 